\title{
EFEITO DE INTEGRAÇÃO ENTRE LAVOURA E PECUÁRIA, SOB PLANTIO DIRETO, EM ALGUNS ATRIBUTOS FÍSICOS DO SOLO APÓS DEZ ANOS (1)
}

\author{
SILVIO TULIO SPERA $\left(2^{*}\right)$; HENRIQUE PEREIRA DOS SANTOS $(3,5)$; \\ RENATO SERENA FONTANELI (4,5); GILBERTO OMAR TOMM $(3,5)$
}

\begin{abstract}
RESUMO
O pisoteio de bovinos em áreas de lavouras pode agravar a compactação do solo, entretanto as informações sobre esse problema são limitadas. Este trabalho teve por objetivo avaliar algumas características físicas de solo em LVd típico, em Coxilha (RS), após dez anos de estabelecimento de seis sistemas de produção integração lavourapecuária. Os tratamentos foram distribuídos em blocos ao acaso com quatro repetições. Foram avaliados também os atributos físicos do solo de um fragmento de floresta subtropical adjacente ao experimento. As culturas, tanto as de inverno como as de verão foram manejadas com sistema plantio direto. Foram comparados os sistemas e os valores dos atributos físicos do solo em cada sistema nas camadas de 0,0-0,05 m ou de 0,0-0,02 m e de 0,10-0,15 m. A densidade de solo e resistência à penetração aumentaram da camada de 0,0-0,05 m ou 0,0-0,02 m para a camada de $0,10-0,15 \mathrm{~m}$. A floresta subtropical, nas camadas de $0,0-0,05 \mathrm{~m}$ ou de $0,0-0,02 \mathrm{~m}$ e de $0,10-0,15 \mathrm{~m}$, teve menor densidade de solo e resistência à penetração e maior porosidade total e macroporosidade do que a maior parte dos sistemas de produção estudados. Nos solos sob diferentes sistemas de produção integrando lavoura-pecuária, apesar de haver indícios de compactação, esta não atingiu níveis considerados críticos ao desenvolvimento dos cultivos, embora o sistema trigo/soja e pastagem de aveia preta + ervilhaca + azevém/pastagem de milheto tenha mostrado os valores de atributos físicos menos favoráveis às plantas.
\end{abstract}

Palavras-chave: rotação de culturas, integração lavoura-pecuária, densidade do solo.

\section{ABSTRACT \\ EFFECT OF CROP-LIVESTOCK UNDER NO-TILLAGE ON SOME SOIL PHYSICAL ATTRIBUTES AFTER TEN YEARS}

Even though raising cattle at crop fields can increase soil compaction, there is scarce information on this problem. This study aimed to evaluate some physical characteristics of soil in a typical Dystrophic Red Latosol (typical dystrophic Hapludox) in the county of Coxilha, State of Rio Grande do Sul, Brazil, after ten years of establishment of six ley farm production systems. The treatments were arranged in blocks with four replications. We also evaluated the fertility of the soil of a subtropical forest fragment adjacent to the experiment. Both winter and summer crops were established under no-tillage. Cropping systems and soil of different sampling depths were compared using the orthogonal contrast procedure. We compared the systems and values of the physical characteristics of soil in each system in the layers of $0.0-0.05 \mathrm{~m}$ or $0-0.02 \mathrm{~m}$ and also $0.10-0.15 \mathrm{~m}$. Soil bulk density and penetration resistance were lower in the layer of $0-0.05 \mathrm{~m}$ or $0-0.02 \mathrm{~m}$. The subtropical forest showed highest soil bulk density and soil penetration resistance and lowest total porosity and macroporosity than most systems studied. The soils under different ley farm production systems, despite showing signs of degradation, did not reach levels considered critical to the development of crops. The system wheat/soybean and black oat + vetch + rye grass / pearl millet pasture (IV) presented the worst physical attributes to plant development.

Keys word: crop rotation, ley farming, soil bulk density.

(1) Recebido para publicação em 22 de junho de 2009 e aceito em 23 de março de 2010.

(²) Embrapa Trigo, Caixa Postal 451, 99001-970 Passo Fundo (RS). Doutorando do curso de pós-graduação em Agronomia - Produção Vegetal na UPF-FAMV. E-mail: spera@cnpt.embrapa.br ${ }^{*}$ ) Autor correspondente.

(3) Embrapa Trigo. E-mail: hpsantos@cnpt.embrapa.br; tomm@cnpt.embrapa.br.

$\left({ }^{4}\right)$ Embrapa Trigo e Faculdade de Agronomia e Medicina Veterinária-FAMV, Universidade de Passo Fundo, Caixa Postal 611, $99052-900$ Passo Fundo (RS). E-mail: renatof@cnpt.embrapa.br.

(5) Bolsista CNPq-PQ. 


\section{INTRODUÇÃO}

Os Latossolos pertencem a uma classe de solos de suma importância, tendo em vista o potencial de produção e a extensão de área que ocupam no planalto sulriograndense (SECCO et al., 2005). Estabelecer sistemas de manejo conservacionistas que objetivam a sustentabilidade desses solos é de grande interesse para a região. Do ponto de vista técnico, um sistema de manejo deve contribuir para a manutenção ou melhoria da qualidade do solo e do ambiente, bem como para a obtenção de rendimentos adequados das culturas em longo prazo (COSTA et al., 2003; SECCO et al., 2005). Nesse contexto, o sistema plantio direto, quando realizado adequadamente, pode possibilitar a recuperação e a preservação da estrutura do solo. De acordo com AlbUQUERQUE et al. (2005), a recuperação de solos degradados mediante uso de plantas de cobertura foi mais efetiva quando foram associadas ao preparo reduzido, evidenciando a importância de sistemas de manejo de solo com baixo revolvimento e alto aporte de resíduos vegetais para aumentar o carbono do solo.

A relação entre o manejo e a qualidade do solo pode ser avaliada pelo efeito nas propriedades físicas, químicas e biológicas do solo (DA Ros et al., 1997; Albuquerque et al., 2001; Costa et al., 2003; SAntos et al., 2001; 2006). O efeito do manejo sobre as propriedades físicas do solo é dependente da textura e mineralogia, as quais influenciam a resistência e a resiliência do solo à determinada prática agrícola (COSTA et al., 2003; SPERA et al., 2006). A resistência mecânica do solo à penetração aumenta com a compactação do solo, sendo restritiva ao crescimento radicular acima de valores que variam de 1,5 a 3,0 kgf cm${ }^{-2}$ (BEUTLER et al., 2001).

No sistema plantio direto, o solo é submetido à menor intensidade de tráfego, porém, não é revolvido, tendendo à compactação. A compactação tem sido verificada pelo aumento da densidade do solo e da relação entre macro e microporosidade (AlbuQueRQuE et al., 1995; SECCO et al., 2005). Todavia, segundo STONE e Silveira (2001), Costa et al. (2003) e Marcolan e ANGHINONI (2006), com o passar dos anos, a densidade do solo com sistema plantio direto pode diminuir parcialmente, em consequência do aumento de matéria orgânica, que melhora a estrutura do solo. Com a porosidade total e macroporosidade pode também ocorrer o inverso. Esse processo pode variar com o tipo de manejo e a profundidade, e também com o sistema de rotação de culturas. Vários trabalhos, que associam o sistema plantio direto a sistemas de rotação de culturas ou sistemas de produção de grãos com elevada adição de resíduos vegetais, têm mostrado efeitos benéficos ao estado estrutural do solo (AlbuQuerQue et al., 1995; CAmpos et al., 1995). Contudo, trabalhos sobre sistemas de produção de grãos com pastagens anuais de inverno e de verão, sob sistema plantio direto, quantificando as oscilações nos atributos físicos do solo, ainda são escassos no Sul do Brasil.

Este trabalho teve como objetivo avaliar o efeito da integração entre lavoura e pecuária nos atributos físicos do solo, após dez anos de cultivo.

\section{MATERIAL E MÉTODOS}

O experimento foi desenvolvido, no município de Coxilha (RS), no período entre 1995 e 2005, em Latossolo Vermelho Distrófico típico (STRECK et al., 2002). Nesta área, antes da instalação do experimento, eram cultivadas lavouras de trigo, no inverno, e de soja, no verão, com sistema plantio direto, durante vários anos.

A análise granulométrica do solo indicou $540 \mathrm{~g}$ $\mathrm{kg}^{-1}$ de argila, $203 \mathrm{~g} \mathrm{~kg}^{-1}$ de silte e $257 \mathrm{~g} \mathrm{~kg}^{-1}$ de areia na camada 0,0-0,05 m e, respectivamente, $554 \mathrm{~g} \mathrm{~kg}^{-1}, 197 \mathrm{~g}$ $\mathrm{kg}^{-1}$ e $249 \mathrm{~g} \mathrm{~kg}^{-1}$ na camada $0,10-0,15 \mathrm{~m}$. Os teores de matéria orgânica determinados nas camadas foram, respectivamente, $41 \mathrm{~g} \mathrm{~kg}^{-1} \mathrm{e} 33 \mathrm{~g} \mathrm{~kg}^{-1}$.

Os tratamentos consistiram em seis sistemas de produção com integração lavoura-pecuária: I) trigo/ soja e pastagem de aveia preta + ervilhaca/milho; II) trigo/soja e pastagem de aveia preta + ervilhaca + azevém/milho; III) trigo/soja e pastagem de aveia preta + ervilhaca/pastagem de milheto; IV) trigo/ soja e pastagem de aveia preta + ervilhaca + azevém/ pastagem de milheto; V) trigo/soja, aveia branca/soja e pastagem de aveia preta + ervilhaca/pastagem de milheto; e VI) trigo/soja, aveia branca/soja e pastagem de aveia preta + ervilhaca + azevém/pastagem de milheto (Tabela 1). Amostras de solo também foram coletadas em um fragmento de floresta subtropical adjacente ao experimento. O delineamento experimental foi em blocos completos ao acaso com quatro repetições. A área das parcelas era de $20 \mathrm{~m}$ de comprimento e 10 $\mathrm{m}$ de largura. Tanto as culturas de inverno como as de verão, foram estabelecidas sob plantio direto.

Quatro anos antes da instalação do experimento foi efetuada calagem com calcário dolomítico, com base no método SMP (pH 6,0). O experimento teve início em abril de 1995, com a semeadura da safra de inverno. Desde então, as adubações de manutenção das safras seguintes foram realizadas de acordo com a indicação para cada cultura (SOCIEDADE... 2004), com base nos resultados de análise de solo.

Em abril de 2001 e de 2003 e em setembro de 2005, foi coletada uma amostra indeformada de solo em cada parcela nas profundidades de 0,0-0,05 m (2001) ou de 0,0-0,02 m (2003 e 2005), conforme o tipo de anel disponível, e de 0,10-0,15 m, tendo sido observado nestas camadas, selamento superficial e compactação 


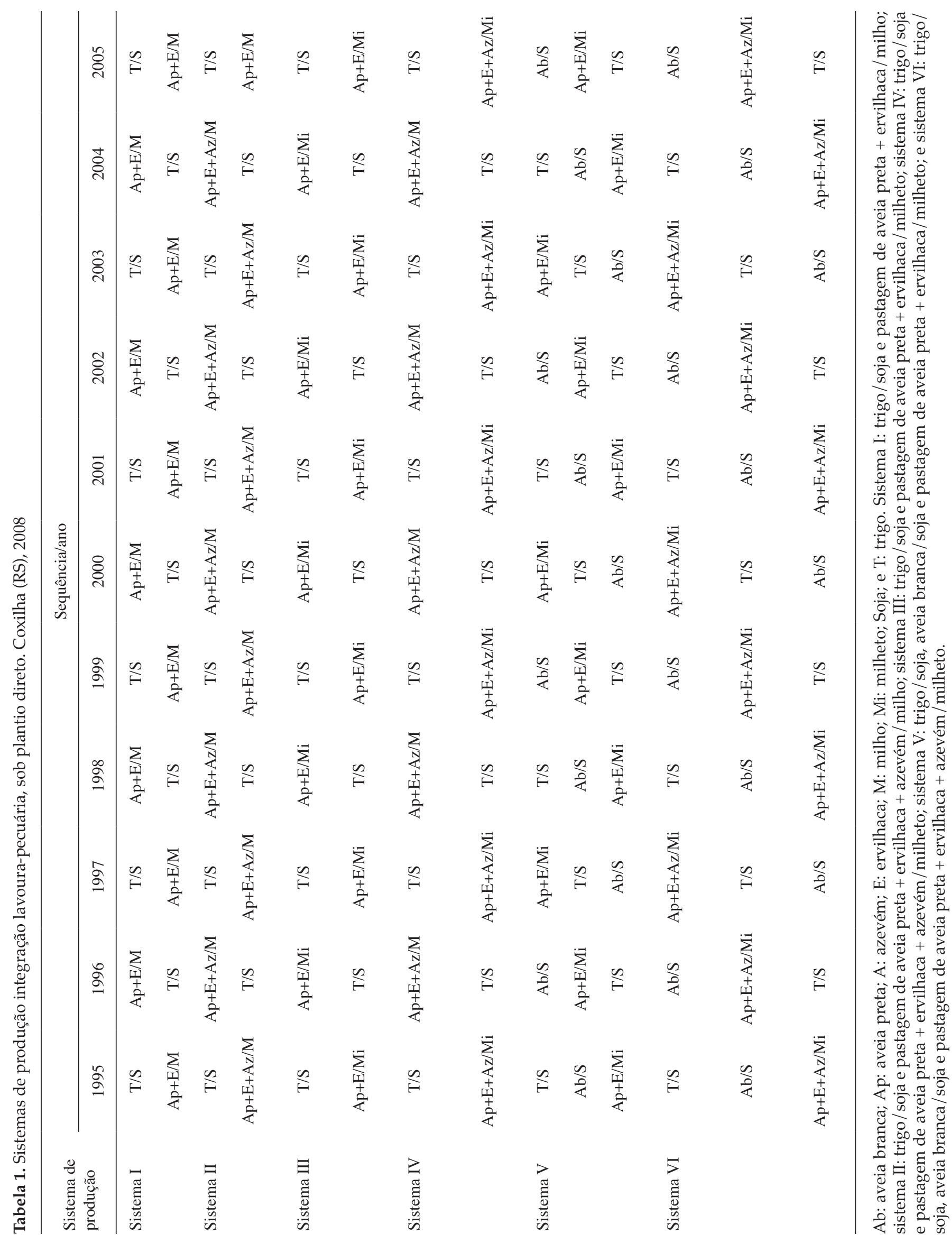


(Spera e Faganello, 2000). Na floresta subtropical, situada ao lado do experimento, foram também coletadas amostras, nas mesmas profundidades, em quatro repetições. Para determinar densidade do solo e porosidade total, foi usado o método do anel volumétrico. A microporosidade foi obtida na mesa de tensão a 0,60 m de coluna de água e a macroporosidade calculada pela diferença entre a porosidade total e a microporosidade, conforme EMBRAPA, 1997. A resistência mecânica à penetração foi determinada com penetrômetro de solo Soiltest modelo S-210, sendo tomadas em cada parcela doze leituras por camada estudada, no mesmo local de coleta de solo com anéis. As condições de umidade do solo no momento da avaliação eram homogêneas e próximas a $70 \%$ da capacidade de campo (cerca de $0,110 \mathrm{~m}^{3} \mathrm{~m}^{-3}$ ).

Os diversos sistemas de produção com integração lavoura-pecuária foram comparados através de contrastes ortogonais, dentro de cada ano, para cada atributo de física do solo, em determinada camada. As profundidades de amostragem de solo foram avaliadas por meio de contrastes ortogonais, levando-se em conta o desdobramento dos graus de liberdade do erro (SAS, 2003). Além disso, os diversos sistemas de produção integração lavoura + pecuária foram comparados entre os diversos anos, em cada atributo de física do solo e profundidade de amostragem. As médias da análise conjunta dos anos foram comparadas pelo teste de Duncan ao nível de 5\% de probabilidade de erro.

\section{RESULTADOS E DISCUSSÃO}

A principal distinção entre os sistemas de produção com integração de lavoura-pecuária (SPILP) consistiu no número de safras cultivadas com pastagens e no período sob pastejo em cada sistema. Nos sistemas I e II a rotação foi bianual e, nesse período, somente a cada dois invernos houve cultivo e pastejo de gramíneas forrageiras de inverno. Nos sistemas III e IV, a rotação também foi bianual e, nesse período, houve um inverno e um verão com cultivo e pastejo. Nos sistemas V e VI, a rotação foi de três anos e, nesse período, houve dois anos com cultivo de lavouras de inverno e de verão e um ano com cultivo e pastejo pastagens de inverno e de verão. Estas rotações resultaram em elevada intensidade de trânsito de máquinas para operações de semeadura e de tratamento fitossanitário, de colheitas e em alta frequência de pisoteio de diferentes bovinos.

\section{Densidade do solo}

Foram realizadas três avaliações, em maio de 2001, em maio de 2003 e em setembro de 2005. Nas avaliações de 2003 e 2005, o valor da densidade do solo (Tabela 2), em todos os SPILP, foi menor do que o verificado nos sistemas e na camada de 0,0-0,02 ou de 0,0-0,05, em 2001 (SPERA et al., 2006). Na continuidade do trabalho sob sistema plantio direto, em todos os SPILP estudados e na camada superficial, houve diminuição da compactação do solo. De acordo com Costa et al. (2003), com o passar dos anos, a densidade do solo sob sistema plantio direto pode diminuir, parcialmente, em consequência do nível de matéria orgânica na camada superficial, melhorando a estrutura do solo. Nesta mesma ocasião, o teor de matéria orgânica de solo, em todas as camadas e SPILP, em 2003, foi maior que o de 2001, que eram, respectivamente, nas camadas: $0,0-0,05 \mathrm{~m}=41 \mathrm{~g} \mathrm{dm}^{-3}$; $0,05-0,10 \mathrm{~m}=36 \mathrm{~g} \mathrm{dm}^{-3} ; 0,10-0,15 \mathrm{~m}=33 \mathrm{~g} \mathrm{dm}^{-3}$; e 0,15$0,20 \mathrm{~m}=32 \mathrm{~g} \mathrm{dm}^{-3}$. Estes valores podem variar com o tipo e a profundidade do solo e, também com o sistema de rotação de culturas. Segundo MARCOLAN e ANGHINONI (2006) o uso do solo com sistema plantio direto durante um período de quatro anos após o revolvimento foi suficiente para a recomposição dos atributos físicos do solo a uma condição próxima da original, uma vez, no estudos desses autores, os atributos não se diferenciaram dos sistemas de produção de oito e 12 anos de cultivo.

Em 2001, na avaliação dos SPILP, houve diferença entre os valores de densidade de solo somente entre os sistemas II e V, e na camada superficial (Tabela 2), resultados que foram relatados no trabalho de SPERA et al. (2006). No sistema $\mathrm{V}$ verificou-se na camada de 0,0-0,05 m densidade de solo maior que na do sistema II. O solo da floresta subtropical foi de baixo valor de densidade em ambas as camadas. Os valores da floresta são menores que as dos SPILP, pois, nesses sistemas, o solo foi submetido a operações de revolvimento em época anterior, ao trânsito de máquinas e implementos agrícolas, e ao pisoteio animal, provocando incremento da densidade em relação ao solo da floresta subtropical, que preservou a condição físico-química natural, sem efeito antrópico. SPERA et al. (2004), estudando sistemas de produção com pastagens, em Latossolo Vermelho, verificaram que os valores de densidade de solo nas camadas de 0,0-0,05 e de 0,10-0,15 m foram iguais nas rotações trigo/soja, ervilhaca/milho e aveia branca/soja; trigo/soja, pastagem de aveia preta + ervilhaca/milho e aveia branca/soja; pastagem perene de inverno e pastagem perene de verão. Mas estes valores de densidade foram maiores que os de floresta subtropical.

Em 2003 e em 2005, não se constataram diferenças entre a densidade de solo, em ambas as camadas estudadas (resultados não apresentados) dos SPILP. Em trabalho desenvolvido por Silva et al. (2000), somente com pastagens anuais de inverno e a cultura de milho no verão, estabelecidas com sistema plantio direto, não foi observada diferença na densidade de solo entre as áreas pastejadas e não pastejadas. De acordo com 
os mesmos autores, o pisoteio animal não teve efeito sobre a densidade de solo, possivelmente pelo fato de o resíduo da pastagem permanecer próximo a $1,0 \mathrm{th} \mathrm{ha}^{-1}$ de matéria seca. Por outro lado, em 2003, nos sistemas I e III, os valores de densidade de solo foram maiores em ambas as camadas estudadas, quando comparados com a floresta subtropical. Em 2005, porém, em todos os SPILP, o valor de densidade foi mais elevado do que na floresta subtropical, na camada de 0,10-0,15 m (resultados não apresentados). SANTOS et al. (2006), também não observaram diferenças de densidade de solo entre os SPILP, em LVd típico. No presente trabalho, assim como em SANTOS et al. (2006), 10 a 15 bovinos foram colocados para pastar durante o dia e em solo relativamente seco, consumindo em um ou dois dias toda a forragem ofertada. Considerando-se que a densidade tem sido um dos parâmetros usados para avaliação do estado estrutural do solo, as condições verificadas nos sistemas estudados permitem afirmar que não houve indícios de severa compactação de solo, apesar de os valores observados na superfície situaremse próximos dos valores considerados por RESENDE (1995) como críticos para Latossolos argilosos $(<1,40)$, com grau de saturação hídrica abaixo de 50\%.

Em função das diferenças de intensidade das ações de manejo antrópico, seriam esperados maiores contrastes entre os resultados da avaliação dos atributos físicos de solo. SAlTon et al. (2001) já haviam constatado, porém, que isso não foi verificado ao se comparar os sistemas. TREIN et al. (1991) verificaram, em Argissolo Vermelho com lotação elevada de animais (200 U.A.) e durante 40 horas, aumento da densidade do solo de 1,39 para 1,56 $\mathrm{Mg} \mathrm{m}^{-3}$, após pastejo. AlbuQuerQue et al. (1995) observaram em Latossolo Vermelho-Escuro distrófico, diferenças entre sistemas de rotação de culturas somente na camada de 0,01 a 0,08 m, na qual a monocultura trigo / soja manifestou maior densidade do que os sistemas trigo/soja e aveia preta + ervilhaca; e trigo/soja, aveia preta/soja e aveia preta/soja. STONE e SILVEIRA (2001) em Latossolo Vermelho Distrófico perférrico, tiveram que as rotações soja/trigo, soja/trigo/soja/feijão/arroz/ feijão e arroz/feijão mostraram maior densidade na camada de 0,0-0,10 m. Contudo, no trabalho destes, os tratamentos com rotação trienal foram semelhantes aos sistemas de sucessão milho/feijão e arroz consorciado com calopogônio / feijão.

Houve diferença na densidade entre as camadas nos dois primeiros SPILP e na floresta subtropical, em 2001. Estes resultados constaram em SPERA et al. (2006). Em todos os sistemas, em 2003 e 2005 (resultados não apresentados), a densidade foi maior na camada de 0,10 0,15 m. Resultados comparáveis foram observados por Trein et al. (1991), Torres e Saraiva (1999), Albuquerque et al. (2001) e SPERA et al. (2004). A maior densidade na camada de 0,10-0,15 m indica compactação de solo nessa profundidade. Esse processo tem sido atribuído, conforme o uso do solo, ao tráfego de máquinas (ANjos et al., 1994) e ao pisoteio por animais (Trein et al., 1991). Neste estudo, a maior densidade verificada na camada de 0,10-0,15 m pode ser atribuída à presença residual de camada compactada resultante de operações anteriores de preparo de solo com aração e gradagem, associadas ao pisoteio promovido pelos bovinos, nas parcelas sob cultivo de forrageiras.

\section{Porosidade total}

Na maior parte dos SPILP, em 2003 e em todos os SPILP, em 2005, a porosidade total, na camada de 0,0-0,05 m, revelou valores maiores do que na avaliação realizada, em 2001, conforme resultados apresentados por SPERA et al. (2006). De acordo com Marcolan e ANGHINONI (2006), com o passar dos anos, a porosidade total do solo com sistema plantio direto pode aumentar parcialmente, com a melhoria da estrutura do solo.

Em todos os anos estudados, não houve diferença quanto à porosidade total entre os SPILP (Tabela 2), de acordo com resultados apresentados por SPERA et al. (2006). Silva et al. (2000) trabalhando com pastagens anuais de inverno e a cultura do milho, no verão observaram resultados concordantes. $\mathrm{Na}$ maioria dos anos estudados, o solo da floresta subtropical estava com maior porosidade total, em relação a todos os SPILP estudados, refletindo as condições naturais de estruturação dos Latossolos. Nesse caso, em relação à floresta subtropical, verificou-semenormacroporosidade em todos os SPILP estudados, com consequente redução na porosidade total. Essa redução pode ser atribuída ao efeito de alterações físicas resultantes de atividades antrópicas intensas como o trânsito frequente de máquinas e pisoteio (TORRES e SARAIVA, 1999).

SPERA et al. (2004) observaram que as rotações trigo/soja, ervilhaca/milho e aveia branca/soja; trigo/ soja, pastagem de aveia preta + ervilhaca/milho e aveia branca/soja; e pastagem perene de inverno e pastagem perene de verão tiveram menor porosidade total do que a floresta subtropical, nas camadas de 0,0-0,05 m e de 0,10-0,15 m. Albuquerque et al. (1995) verificaram na monocultura trigo/soja menor porosidade total na camada de 0,01-0,08 $\mathrm{m}$ do que nas rotações: trigo/soja, aveia preta/soja e aveia preta + ervilhaca/milho e aveia preta/soja, aveia preta/soja e trigo/ soja. STONE e SILVEIRA (2001) observaram nas rotações milho/feijão, milho/ feijão/milho/feijão/arroz/feijão, arroz consorciado com calopogônio/ feijão, arroz / feijão e soja/trigo/soja / feijão/arroz/feijão porosidade total mais elevada na camada de 0,0-0,10 m. 
Em 2001, houve diferença na porosidade total das profundidades em somente um SPILP e na floresta subtropical, de acordo com resultados apresentados por SPERA et al. (2006). No sistema II e na floresta subtropical, a porosidade total foi maior na camada de 0,0-0,05 m. Estes resultados estão de acordo com obtidos por SPERA et al. (2004) estudando SPILP. Porém, no sistema II, em relação aos demais tratamentos, verifica-se que pode ter havido ação favorável do sistema radicular das culturas, principalmente do milho na reestruturação da porosidade da camada 0,0-0,05 m. Em 2003 e 2005, a porosidade total da maioria dos SPILP estudados foram maiores na camada de $0-0,02 \mathrm{~m}$, ou de $0-0,05$ m. Na floresta subtropical, o acúmulo de serrapilheira na camada superficial favoreceu, além da redução da densidade, aumento de porosidade total. Resultados iguais também foram obtidos por AlbuQueRQue et al. (1995), com sistemas de manejo de solo que incluíam rotação de culturas, em mesmo tipo de solo, nos quais a porosidade total foi maior na camada $0,01-0,08 \mathrm{~m}$ em relação à de 0,08-0,16 m.

\section{Microporosidade}

Em 2003, todos os SPILP tiveram maior microporosidade na camada de 0,0-0,05 m, em relação ao observado em 2001 (SPERA et al., 2006). Segundo Marcolan e Anghinoni (2006), com o passar dos anos, a microporosidade sob sistema plantio direto pode aumentar, mesmo com a melhoria da estrutura do solo.

Em 2001, entre os SPILP, houve diferenças entre as médias de microporosidade (Tabela 2), de acordo com Spera et al. (2006). No sistema IV, na camada de 0,0$0,05 \mathrm{~m}$, houve maior microporosidade que no sistema I, enquanto no sistema VI ocorreu maior microporosidade que no sistema I, em ambas as camadas. Além disso, no sistema $V$ também houve, na camada de 0,10-0,15 $\mathrm{m}$, maior microporosidade que no sistema I. Em $2001 \mathrm{e}$ 2003, na floresta subtropical, na camada de 0,0-0,05 m, notou-se maior microporosidade que em todos os SPILP estudados. A floresta subtropical contém maior volume de microporos do que os SPILP estudados, uma vez não foi submetida a perturbações inerentes às atividades agrícolas. Resultados comparáveis de microporosidade foram obtidos por SPERA et al. (2004), que observaram nos sistemas trigo/soja, ervilhaca/milho e aveia branca/ soja; trigo/soja, pastagem de aveia preta + ervilhaca/ milho e aveia branca/soja, e na pastagem perene de estação fria e na pastagem perene de estação quente, valores menores que os da floresta subtropical. Ademais, no sistema II também houve, na camada de 0,0-0,05 m, menor microporosidade que os sistemas III, IV, V e VI. STONE e SiLVEIRA (2001) observaram que as rotações soja / trigo, soja/trigo/soja/feijão/arroz/feijão, milho/feijão e arroz/feijão tiveram microporosidade mais elevada na camada de 0,0-0,10 m.
Em 2003, não houve diferença entre as médias de microporosidade dos SPILP (resultados não apresentados). Resultados comparáveis foram obtidos por SPERA et al. (2004), trabalhando com SPILP. Em 2005, no sistema IV, na camada de 0,0-0,02 m, verificou-se maior microporosidade que naquelas dos sistemas I, II e III. A microporosidade da camada de 0,10-0,15 m dos sistemas V e VI foram que do sistema I. O solo da floresta subtropical manifestou, na camada de 0,10-0,15 m (resultados não apresentados), menor microporosidade que nas camadas dos SPILP estudados.

Em 2001 e 2003, não houve diferença entre a microporosidade das profundidades dos solos dos SPILP. Resultados similares foram constatados por Albuguerque et al. (1995) e Andreola et al. (2000) ao estudarem diferentes tipos de manejos de solo e de rotação de culturas. Nessas duas avaliações (2001 e 2003), a microporosidade da camada de $0,0-0,05 \mathrm{~m}$ da floresta subtropical foi maior. Resultados concordantes foram obtidos por AlbUQUERQue et al. (2001). Em 2005, o valor da microporosidade na maioria dos SPILP estudados foram maiores na camada de 0,10-0,15 m.

\section{Macroporosidade}

Os valores de macroporosidade dos sistemas I, III, V e VI, em 2003 foram menores, que os observados na mesma área em 2001 (SPERA et al., 2006). Isto indica que houve, nesse período, intensificação da compactação do solo. De acordo com Marcolan e AnghinONi (2006), com o passar dos anos, a macroporosidade do solo com sistema plantio direto pode aumentar, devido a recuperação da estrutura do solo. De acordo com estes autores, valores de macroporosidade abaixo de $0,10 \mathrm{~m}^{3}$ $\mathrm{m}^{-3}$, são desfavoráveis ao enraizamento. Em 2001, houve diferenças entre as médias de macroporosidade dos SPILP (Tabela 2), conforme resultados apresentados por SPERA et al. (2006). No sistema II ocorreu na camada de 0,0-0,05 m maior macroporosidade do que os sistemas III, IV, V e VI. Como era esperado, verificou-se no solo da floresta subtropical, em ambas as camadas, maior macroporosidade que a dos SPLIP estudados. Assim, a microporosidade e a macroporosidade foram afetadas pelos SPILP estudados. Segundo Bouma (1991), os macroporos estão relacionados com processos vitais para as plantas, devendo o ambiente edáfico ser preservado. A redução da macroporosidade tende a se refletir, significativamente ou não, na porosidade total e no aumento de densidade de solo. AlbuQuerQue et al. (1995) e ANDREOLA et al. (2000), estudando sistemas de rotação de culturas, não constataram diferenças nos valores de macroporosidade entre os SPILP estudados. STONE e SILVEIRA (2001) observaram que nos sistemas de rotação com arroz consorciado com calopogônio / feijão e milho / feijão / milho / feijão / arroz / feijão, na camada de 0,0-0,10 $\mathrm{m}$, ocorreram maiores valores de macroporosidade. 
Tabela 2. Valores médios de densidade do solo, porosidade total, microporosidade, macroporosidade e resistência mecânica à penetração, nas camadas de 0,0-0,05 ou 0,0-0,02 cm e 0,10-0,15 cm de profundidade, determinado em 2001, 2003 e 2005, em seis sistemas de produção integração lavoura-pecuária. Embrapa Trigo, Coxilha (RS), 2008

\begin{tabular}{|c|c|c|c|c|c|c|}
\hline \multirow{3}{*}{$\begin{array}{l}\text { Sistema } \\
\text { de produção }\end{array}$} & \multicolumn{6}{|c|}{ Camada (m) } \\
\hline & \multicolumn{3}{|c|}{$0,0-0,05$ ou $0,0-0,02$} & \multicolumn{3}{|c|}{$0,10-0,15$} \\
\hline & 2001 & 2003 & 2005 & 2001 & 2003 & 2005 \\
\hline \multicolumn{7}{|c|}{ Densidade do solo $\left(\mathrm{Mg} \mathrm{m}^{-3}\right)$} \\
\hline Sistema I & $1,27 \mathrm{~A}$ & $1,21 \mathrm{~A}$ & $1,04 \mathrm{~B}$ & $1,34 \mathrm{~A}$ & $1,34 \mathrm{~A}$ & $1,29 \mathrm{~A}$ \\
\hline Sistema II & $1,23 \mathrm{~A}$ & $1,20 \mathrm{~A}$ & $1,05 \mathrm{~B}$ & $1,31 \mathrm{~A}$ & $1,33 \mathrm{~A}$ & $1,35 \mathrm{~A}$ \\
\hline Sistema III & $1,27 \mathrm{~A}$ & $1,21 \mathrm{~A}$ & $1,04 \mathrm{~B}$ & $1,30 \mathrm{~A}$ & $1,31 \mathrm{~A}$ & $1,35 \mathrm{~A}$ \\
\hline Sistema IV & $1,27 \mathrm{~A}$ & $1,18 \mathrm{AB}$ & $1,12 \mathrm{~B}$ & $1,31 \mathrm{~A}$ & $1,31 \mathrm{~A}$ & $1,32 \mathrm{~A}$ \\
\hline Sistema V & $1,30 \mathrm{~A}$ & $1,16 \mathrm{~B}$ & $1,06 \mathrm{C}$ & $1,31 \mathrm{~A}$ & $1,28 \mathrm{~A}$ & $1,33 \mathrm{~A}$ \\
\hline Sistema VI & $1,28 \mathrm{~A}$ & $1,15 \mathrm{~B}$ & $1,03 \mathrm{C}$ & $1,30 \mathrm{~A}$ & $1,31 \mathrm{~A}$ & $1,34 \mathrm{~A}$ \\
\hline Floresta & $0,91 \mathrm{~A}$ & $1,08 \mathrm{~A}$ & $0,96 \mathrm{~A}$ & $1,07 \mathrm{~B}$ & $1,09 \mathrm{~B}$ & $1,22 \mathrm{~A}$ \\
\hline \multicolumn{7}{|c|}{ Porosidade total $\left(\mathrm{m}^{3} \mathrm{~m}^{-3}\right)$} \\
\hline Sistema I & $0,518 \mathrm{~B}$ & $0,520 \mathrm{~B}$ & $0,579 \mathrm{~A}$ & 0,496 A & $0,490 \mathrm{~A}$ & $0,500 \mathrm{~A}$ \\
\hline Sistema II & $0,535 \mathrm{AB}$ & $0,520 \mathrm{~B}$ & $0,566 \mathrm{~A}$ & $0,504 \mathrm{~A}$ & $0,480 \mathrm{~B}$ & $0,483 \mathrm{AB}$ \\
\hline Sistema III & $0,517 \mathrm{~B}$ & $0,530 \mathrm{~B}$ & $0,570 \mathrm{~A}$ & $0,512 \mathrm{~A}$ & $0,490 \mathrm{~A}$ & $0,492 \mathrm{~A}$ \\
\hline Sistema IV & $0,519 \mathrm{AB}$ & $0,510 \mathrm{~B}$ & $0,559 \mathrm{~A}$ & $0,504 \mathrm{~A}$ & $0,490 \mathrm{~A}$ & $0,498 \mathrm{~A}$ \\
\hline Sistema V & $0,508 \mathrm{~B}$ & $0,520 \mathrm{~B}$ & $0,571 \mathrm{~A}$ & $0,507 \mathrm{~A}$ & $0,490 \mathrm{~A}$ & $0,502 \mathrm{~A}$ \\
\hline Sistema VI & $0,513 \mathrm{~B}$ & $0,530 \mathrm{~B}$ & $0,576 \mathrm{~A}$ & $0,509 \mathrm{~A}$ & $0,490 \mathrm{~A}$ & $0,502 \mathrm{~A}$ \\
\hline Floresta & $0,663 \mathrm{~A}$ & $0,580 \mathrm{~B}$ & $0,596 \mathrm{AB}$ & $0,613 \mathrm{~A}$ & $0,540 \mathrm{~B}$ & $0,549 \mathrm{~B}$ \\
\hline \multicolumn{7}{|c|}{ Microporosidade $\left(\mathrm{m}^{3} \mathrm{~m}^{-3}\right)$} \\
\hline Sistema I & $0,389 \mathrm{~B}$ & $0,390 \mathrm{~B}$ & $0,423 \mathrm{~A}$ & $0,390 \mathrm{~A}$ & $0,400 \mathrm{~A}$ & $0,397 \mathrm{~A}$ \\
\hline Sistema II & $0,378 \mathrm{~B}$ & $0,400 \mathrm{~B}$ & $0,425 \mathrm{~A}$ & $0,401 \mathrm{~A}$ & $0,390 \mathrm{~A}$ & $0,407 \mathrm{~A}$ \\
\hline Sistema III & $0,401 \mathrm{~A}$ & $0,420 \mathrm{~A}$ & $0,423 \mathrm{~A}$ & $0,403 \mathrm{~A}$ & $0,400 \mathrm{~A}$ & $0,405 \mathrm{~A}$ \\
\hline Sistema IV & $0,410 \mathrm{~B}$ & $0,390 \mathrm{~B}$ & $0,452 \mathrm{~A}$ & $0,405 \mathrm{~A}$ & $0,390 \mathrm{~A}$ & $0,404 \mathrm{~A}$ \\
\hline Sistema V & $0,406 \mathrm{~B}$ & $0,390 \mathrm{~B}$ & $0,432 \mathrm{~A}$ & $0,411 \mathrm{~A}$ & $0,400 \mathrm{~A}$ & $0,411 \mathrm{~A}$ \\
\hline Sistema VI & $0,408 \mathrm{AB}$ & $0,400 \mathrm{~B}$ & $0,432 \mathrm{~A}$ & $0,417 \mathrm{~A}$ & $0,410 \mathrm{~A}$ & $0,411 \mathrm{~A}$ \\
\hline Floresta & $0,441 \mathrm{~A}$ & $0,440 \mathrm{~A}$ & $0,436 \mathrm{~A}$ & $0,394 \mathrm{~A}$ & $0,420 \mathrm{~A}$ & $0,427 \mathrm{~A}$ \\
\hline \multicolumn{7}{|c|}{ Macroporosidade $\left(\mathrm{m}^{3} \mathrm{~m}^{-3}\right)$} \\
\hline Sistema I & $0,129 \mathrm{~A}$ & $0,120 \mathrm{~A}$ & $0,156 \mathrm{~A}$ & $0,107 \mathrm{~A}$ & $0,080 \mathrm{~A}$ & $0,103 \mathrm{~A}$ \\
\hline Sistema II & $0,157 \mathrm{~A}$ & $0,120 \mathrm{~A}$ & $0,141 \mathrm{~A}$ & $0,104 \mathrm{~A}$ & $0,080 \mathrm{AB}$ & $0,076 \mathrm{~B}$ \\
\hline Sistema III & $0,116 \mathrm{~A}$ & $0,110 \mathrm{~A}$ & $0,147 \mathrm{~A}$ & $0,109 \mathrm{~A}$ & $0,080 \mathrm{~B}$ & $0,086 \mathrm{AB}$ \\
\hline Sistema IV & $0,110 \mathrm{~A}$ & $0,110 \mathrm{~A}$ & $0,107 \mathrm{~A}$ & $0,099 \mathrm{~A}$ & $0,090 \mathrm{~A}$ & $0,094 \mathrm{~A}$ \\
\hline Sistema V & $0,102 \mathrm{~B}$ & $0,120 \mathrm{AB}$ & $0,139 \mathrm{~A}$ & $0,095 \mathrm{~A}$ & $0,090 \mathrm{~A}$ & $0,092 \mathrm{~A}$ \\
\hline Sistema VI & $0,105 \mathrm{~B}$ & $0,130 \mathrm{AB}$ & $0,144 \mathrm{~A}$ & $0,093 \mathrm{~A}$ & $0,070 \mathrm{~B}$ & $0,088 \mathrm{AB}$ \\
\hline Floresta & $0,222 \mathrm{~A}$ & $0,140 \mathrm{~B}$ & $0,160 \mathrm{~B}$ & $0,220 \mathrm{~A}$ & $0,130 \mathrm{~B}$ & $0,122 \mathrm{~B}$ \\
\hline \multicolumn{7}{|c|}{ Resistência mecânica à penetração $\left(\mathrm{kgf} \mathrm{cm}^{-2}\right)$} \\
\hline Sistema I & $1,65 \mathrm{~A}$ & $1,84 \mathrm{~A}$ & nd & $2,72 \mathrm{~A}$ & $2,27 \mathrm{~B}$ & nd \\
\hline Sistema II & $1,34 \mathrm{~A}$ & $1,89 \mathrm{~A}$ & nd & $2,78 \mathrm{~A}$ & $2,57 \mathrm{~A}$ & nd \\
\hline Sistema III & $1,95 \mathrm{~A}$ & $1,90 \mathrm{~A}$ & nd & $2,81 \mathrm{~A}$ & 2,42 B & nd \\
\hline Sistema IV & $1,76 \mathrm{~A}$ & $2,02 \mathrm{~A}$ & nd & $2,87 \mathrm{~A}$ & $2,58 \mathrm{~B}$ & nd \\
\hline Sistema V & $1,46 \mathrm{~A}$ & $1,89 \mathrm{~A}$ & nd & $2,69 \mathrm{~A}$ & $2,36 \mathrm{~B}$ & nd \\
\hline Sistema VI & $1,60 \mathrm{~A}$ & $1,73 \mathrm{~A}$ & nd & $2,85 \mathrm{~A}$ & $2,52 \mathrm{~B}$ & nd \\
\hline Floresta & $0,83 \mathrm{~A}$ & $0,96 \mathrm{~A}$ & nd & $1,97 \mathrm{~A}$ & $1,51 \mathrm{~A}$ & nd \\
\hline
\end{tabular}

Sistema I: trigo/soja e pastagem de aveia preta + ervilhaca/milho; sistema II: trigo/soja e pastagem de aveia preta + ervilhaca + azevém/milho; sistema III: trigo/soja e pastagem de aveia preta + ervilhaca/milheto; sistema IV: trigo/soja e pastagem de aveia preta + ervilhaca + azevém/milheto; sistema V: trigo/soja, aveia branca/soja e pastagem de aveia preta + ervilhaca/milheto; sistema VI: trigo/soja, aveia branca/soja e pastagem de aveia preta + ervilhaca + azevém/milheto; e F: floresta subtropical. Médias seguidas da mesma letra por profundidade e sistema, na horizontal, não apresentam diferenças significativas, pelo teste de Duncan ao nível de 5\% de probabilidade de erro; nd: dados não disponíveis. 
Todavia, esta última rotação não diferiu dos sistemas arroz/feijão e milho/feijão. Em 2003, não houve diferença entre os valores de macroporosidade dos sistemas de produção (resultados não apresentados). Em 2005, no sistema IV e na floresta subtropical observouse, na camada de 0,0-0,02 m, maior macroporosidade do que no sistema I (resultados não apresentados). Porém, na camada de 0,10-0,15 m, no sistema I notou-se maior macroporosidade em relação ao sistema II. Na floresta subtropical, entretanto, houve maior macroporosidade que na dos sistemas II, III, V e VI.

Em 2001, foi verificada diferença de macroporosidade do solo entre as camadas em somente um SPILP. O valor de macroporosidade do sistema II foi maior na camada de $0,10-0,15 \mathrm{~m}$ do que na de $0,0-0,05 \mathrm{~m}$. $\mathrm{O}$ maior valor de macroporosidade do sistema II pode ser consequência da maior porosidade total, e pode ser explicado pela da combinação da intensa atividade de crescimento e ação agregadora das raízes de azevém e de milho na reestruturação do solo (STONE et al., 2003). Em 2003, nos sistemas I, II e VI observaram-se maiores valores de macroporosidade na camada de 0,0-0,05 m do que na de 0,10-0,15 m, enquanto, em 2005, ocorreu na maioria dos SPILP. SPERA et al. (2004) constataram resultados semelhantes de macroporosidade somente para alguns SPILP estudados, ou seja, houve diminuição dos valores nos sistemas trigo/soja, trigo/soja, ervilhaca/milho e aveia branca/soja; trigo/soja, aveia preta + ervilhaca/milho e aveia branca/soja; e alfafa para feno.

\section{Resistência à penetração de solo}

Em todos os SPILP e na floresta subtropical, exceto no sistema III, em 2003, foram observados na camada de 0,0-0,05 m, maiores valores de resistência mecânica à penetração, em relação aos valores verificados em 2001 (SPERA et al., 2006). Em 2001, somente dois dos SPILP diferiram entre si na camada de $0,0-0,05 \mathrm{~m}$ quanto à resistência mecânica à penetração (Tabela 2), de acordo com resultados apresentados por SPERA et al. (2006).

No sistema III, houve na camada de 0,0-0,05 m, maior resistência mecânicaà penetraçãodoquenosistema II. O sistema II pode ter minimizado o efeito de pisoteio de bovinos, na camada de 0,0-0,05 m, em relação aos demais tratamentos, pela presença de resíduos culturais de milho. Entretanto, essa diferença foi significativa apenas em relação ao sistema III, caracterizado por um cultivo de inverno e um de verão subsequente com o da pastagem. Dentre as culturas anuais, o resíduo de milho ofereceu maior proteção mecânica ao solo (STONE et al., 2003). Em 2003, não houve, na camada de 0,0-0,05 m, diferença para a resistência mecânica à penetração entre os SPILP, porém, na camada de $0,10-0,15 \mathrm{~m}$, verificou-se o inverso (resultados não apresentados). Nos sistemas
II, IV e VI, a resistência mecânica à penetração foi maior do que no sistema I. Em ambos os anos estudados, no solo da floresta subtropical houve menor resistência mecânica à penetração em comparação com a maioria dos SPILP, em ambas as camadas. Conforme os critérios de Beutler et al. (2001), em ambas as avaliações de resistência à penetração os valores da camada de $0,0-0,05$ $\mathrm{m}$ seriam moderados $\left(1,0\right.$ a $\left.2,0 \mathrm{kgf} \mathrm{cm}^{-2}\right)$, enquanto os da camada de 0,10-0,15 m seriam altos $\left(2,0\right.$ a $\left.4,0 \mathrm{~cm}^{-2}\right)$.

Em ambos os anos estudados e na maioria dos SPILP, e na floresta subtropical, houve diferenças de resistência mecânica à penetração entre camadas de solo e os respectivos valores de umidade atual do solo no momento da leitura com penetrômetro. Em 2001, com exceção do sistema III, a resistência mecânica à penetração foi maior na camada de $0,10-0,15 \mathrm{~m}$ que na camada de 0,0-0,05 m. Na maioria dos SPILP estudados e na floresta subtropical, a resistência à penetração foi menor na camada de $0,0-0,05 \mathrm{~m}$ do que na de $0,10-0,15$ $\mathrm{m}$. Resultados compatíveis de resistência mecânica à penetração foram obtidos por AlbuQuerQue et al. (2001).

Em 2001 e de 2003, os maiores valores de resistência à penetração foram constatados na camada de 0,10-0,15 m em relação à camada superficial, ainda que nesta última tenham ocorrido diretamente os efeitos do pisoteio e do trânsito de máquinas. Esse fato reforça a suposição de KochHANN et al. (1999) e de SPERA et al. (2004) que a compactação de solo abaixo da superfície, observada nos Latossolos Vermelhos do Planalto Médio do Rio Grande do Sul, é resultante de compressão promovida por arados e grades na profundidade de ação desses equipamentos formando "pé-de-grade" ou "pé-de-arado". As diferenças dos valores de densidade do solo, porosidade total, microporosidade e resistência mecânica à penetração de solo entre as camadas, encontradas na floresta subtropical podem ser atribuídas ao acúmulo na superfície, durante longo período, de serrapilheira, que deu origem a uma camada orgânica de solo.

Considerando-se os valores de macroporosidade, porosidade total, densidade e resistência mecânica de solo à penetração (Tabela 2), pôde-se constatar que a estrutura de solo submetida à atividade agropecuária, em comparação à floresta subtropical, indicou degradação em todos os SPILP estudados, porém de média intensidade. De acordo com Silva (1993) e AlbuQuerQue et al. (2005), as atividades antrópicas, por menor que seja a intensidade, alteram as propriedades originais do solo. Considerando-se que os bovinos foram introduzidos para pastejar apenas quando o solo estava relativamente seco, a atividade pecuária dos sistemas produziu alterações de menor impacto do que comumente tem sido observado. TREIN et al. (1991) verificaram, em um experimento, que a resistência 
à penetração de solo antes e após o pastejo por um período de 40 horas, e com a lotação de 200 bovinos por hectare aumentou de 8,4 vezes na camada de 0,0-0,07 $\mathrm{m}$. No presente estudo, esse pastejo foi realizado apenas duas ou três vezes, no inverno, e três a quatro vezes, no verão, com duração de, no máximo, dois dias em cada pastejo, com carga de aproximadamente $12 \mathrm{UA}$, mantendo-se intervalo de 40-60 dias após a retirada dos animais da área para favorecer a rebrota das forrageiras, o que caracterizou lotação animal leve.

Em trabalhos desenvolvidos em Latossolos de Cerrados, MAGALHÃEs et al. (2001) avaliaram a evolução das propriedades físicas densidade do solo e resistência à penetração de áreas manejadas segundo o "Sistema Barreirão" e verificaram que essas propriedades estão relacionadas com a produção de fitomassa seca de pastagens, e os valores mais favoráveis do ponto de vista agronômico destas propriedades físicas ocorrem em condição de maior produção de fitomassa pelas gramíneas. Conforme Trein et al. (1991) e Albuquerque et al. (2001), em sistemas de produção onde há apenas lavouras anuais, pode ocorrer menor alteração nos atributos físicos do que em sistemas onde há integração de lavoura anuais com pecuária. Para SILVA (1993), o processo de melhoramento da estrutura do solo é governado pelo volume, pela extensão e pela agressividade do sistema radicular das espécies componentes dos sistemas de produção, e pastagens têm maior potencial para reestruturar solos do que plantas anuais.

\section{CONCLUSÕES}

1. Nos três anos avaliados não há efeito desfavorável do pisoteio animal sobre a estrutura da superfície do solo;

2. Os valores de macroporosidade, nestes três anos, mantêm-se, de modo geral, abaixo do considerado ideal para o enraizamento e desenvolvimento de plantas.

3. O pisoteio pelo gado bovino, nos sistemas de produção integrando lavoura e pecuária estudados, não proporcionam compactação do solo em níveis considerados críticos à produção vegetal.

\section{REFERÊNCIAS}

ALBUQUERQUE,J.A.;ARGENTON,J.;BAYER, C.; WILDNER, L.P.; KUNTZE, M.A.G. Relação de atributos do solo com a agregação de um Latossolo Vermelho sob sistemas de preparo e plantas de verão para cobertura do solo. Revista Brasileira de Ciência de Solo, v.29, p.415-424, 2005.

ALBUQUERQUE, J.A.; REINERT, D.J.; FIORIN, J.E.; RUEDELL, J.; PETRERE, C.; FONTINELLI, F. Rotação de culturas e sistemas de manejo do solo: efeito sobre a forma da estrutura do solo ao final de sete anos. Revista Brasileira de Ciência do Solo, v.19, p.115-119, 1995.

ALBUQUERQUE, J.A.; SANGOI, L.; ENDER M. Efeitos da integração lavoura-pecuária nas propriedades físicas do solo e características da cultura do milho. Revista Brasileira de Ciência do Solo, v.25, p.717-723, 2001.

ANDREOLA, F.; COSTA, L.M.; OLSZEVSKI, N. Influência da cobertura vegetal de inverno e da adubação orgânica e ou mineral sobre as propriedades físicas de uma Terra Roxa Estruturada. Revista Brasileira de Ciência de Solo, v.24, p.857-865, 2000.

ANJOS, J.T.; UBERTI, A.A.A.; VIZZOTTO, V.J.; LEITE, G.B.; KRIEGER, M. Propriedades físicas em solos sob diferentes sistemas de uso e manejo. Revista Brasileira de Ciência do Solo, v.18, p.139-145, 1994.

BEUTLER, A.N.; SILVA, M.L.N.; CURI, N.; FERREIRA, M.M.; CRUZ, J.C.; PERREIRA FILHO, I.A. Resistência à penetração e permeabilidade de Latossolo Vermelho distrófico típico sob sistemas de manejo na Região dos Cerrados. Revista Brasileira de Ciência do Solo, v.25, p.167-177, 2001.

BOUMA, J. Influence of soil macroporosity on environmental quality. Advances in Agronomy, v.46, p.1-37, 1991.

CAMPOS, B.C.; REINERT, D.J.; NICOLODI, R.; RUEDELL, J.; PETRERE, C. Estabilidade estrutural de um Latossolo Vermelho-Escuro distrófico após sete anos de rotação de culturas e sistemas de manejo do solo. Revista Brasileira de Ciência do Solo, v.19, p.121-126, 1995.

COSTA, F.S.; ALBUQUERQUE, J.A.; BAYER, C.; FOUTOURA, S.M.V.; WOBETO, C. Propriedades físicas de um Latossolo Bruno afetadas pelos sistemas plantio direto e preparo convencional. Revista Brasileira de Ciência do Solo, v.7, p.527-535, 2003.

DA ROS, C.O.; SECCO, D.; FIORIN, J.E.; PETRERE, C.; CADORE, M.A.; PASA, L. Manejo do solo a partir de campo nativo: efeito sobre a forma e estabilidade da estrutura ao final de cinco anos. Revista Brasileira de Ciência do Solo, v.21, p.241-247, 1997.

EMBRAPA. Centro Nacional de Pesquisa de Solos. Manual de métodos de análise de solo. 2.ed. Brasília: SPI, 1997. 212p. (Embrapa Solos. Documentos, 1)

KOCHHANN, R.A.; DENARDIN, J.E.; FAGANELLO, A. É necessária a descontinuidade do sistema plantio direto após dez anos de adoção? Embrapa Trigo: Passo Fundo. 1999. 10p. (Comunicado Técnico Online, 43). Disponível em: www.cnpt. embrapa.br/biblio/p_co43.htm.

MAGALHÃES, R.T.; KLIEMANN, H.J.; OLIVEIRA, I.P. Evolução das propriedades físicas de solos submetidos ao manejo do sistema Barreirão. Pesquisa Agropecuária Tropical, v.31, p.7-13, 2001.

MARCOLAN, A.L.; ANGHINONI, I. Atributos físicos de um Argissolo e rendimento de culturas de acordo com o 
revolvimento do solo em plantio direto. Revista Brasileira de Ciência do Solo, v.23, p.163-170, 2006.

RESENDE, P.C.S. Resistência mecânica e sua variação com a umidade e com a densidade do solo em Latossolo VermelhoEscuro do Cerrado. 1995. 100f. Dissertação (Mestrado em Ciência do Solo), Universidade Estadual Paulista Júlio de Mesquita Filho, Botucatu.

SALTON, J.C.; FABRICIO, A.C.; MACHADO, L.A.Z.; OLIVEIRA, H. Pastoreio da aveia e compactação do solo. Dourados: Embrapa Agropecuária Oeste, 2001. 5p. (Embrapa Agropecuária Oeste. Comunicado Técnico, 48)

SANTOS, H.P.; FONTANELI, R.S.; TOMM, G.O. Efeito de sistemas de produção de grãos e de pastagens sob plantio direto sobre o nível de fertilidade do solo após cinco anos. Revista Brasileira de Ciência do Solo, v.25, p.645-653, 2001.

SANTOS, H.P.; FONTANELI, R.S.; TOMM, G.O.; DENARDIN, J.E. Atributos físicos e químicos de solo em sistemas de produção de grãos envolvendo pastagens anuais sob plantio direto. Pesquisa Agropecuária Gaúcha, v.12, p.73-81, 2006.

SAS INSTITUTE. SAS system for Microsoft Windows version 8.2. Cary, North Caroline: Statistical Analysis Systems, 2003.

SECCO, D.; DA ROS, C.O.; SECCO, J.K.;FIORIN, J.E. Atributos físicos e produtividade de culturas em um Latossolo Vermelho argiloso sob diferentes sistemas de manejo. Revista Brasileira de Ciência do Solo, v.29, p.407-414, 2005.

SILVA, I.F. Formação, estabilidade e qualidade de agregados do solo afetados pelo uso agrícola. 1993. 126f. Tese (Doutorado em Ciência do Solo), Universidade Federal do Rio Grande do Sul, Porto Alegre.

SILVA, M.A.S.; MAFRA, A.L.; ALBUQUERQUE, J.A; ROSA, J.D.; BAYER, C.; MIELNICZUK, J. Propriedades físicas e teor de carbono orgânico de um Argissolo Vermelho sob distintos sistemas de uso e manejo. Revista Brasileira de Ciência do Solo, v.30, p.329-337, 2006.

SILVA, V.R.; REINERT, D.J.; REICHERT, J.M. Densidade do solo, atributos químicos e sistema radicular do milho afetados pelo pastejo e manejo do solo. Revista Brasileira de Ciência do Solo, v.24, p.191-199, 2000.
SOCIEDADE BRASILEIRA DE CIÊNCIA DO SOLO. Comissão de Química e Fertilidade do Solo. Núcleo Regional Sul. Manual de adubação e de calagem para os estados do Rio Grande do Sul e de Santa Catarina. 10.ed. Porto Alegre: SBCS/CQFS-NRS, 2004. 400p.

SPERA, S.T.; FAGANELLO, A. Estresses ocasionados por práticas de manejo de solo. In: BONATO, E.R. (Ed.). Estresses em soja. Passo Fundo: Embrapa Trigo, 2000. p.67-79.

SPERA, S.T.; SANTOS, H.P.; TOMM, G.O.; FONTANELI, R.S. Avaliações de alguns atributos físicos de solo em sistemas de produção de grãos, envolvendo pastagens sob plantio direto. Revista Científica Rural, v.9, p.23-31, 2004.

SPERA, S.T.; SANTOS, H.P.; FONTANELI, R.S.; TOMM, G.O. Efeito de pastagens de inverno e de verão em características físicos do solo, sob plantio direto. Ciência Rural, v.36, p.1.1931.200, 2006.

STONE, L.F.; MOREIRA, J.A.A.; KLUTHCOUSKI, J. Influência das pastagens na melhoria dos atributos físicos-hídricos do solo. In: KLUTHCOUSKI, J.; STONE, L.F.; AIDAR, H. Integração lavoura pecuária. Santo Antônio de Goiás: Embrapa Arroz e Feijão, 2003. p.171-181.

STONE, L.F.; SILVEIRA, P.M. Efeitos do sistema de preparo e da rotação de culturas na porosidade e densidade do solo.

Revista Brasileira de Ciência do Solo, 25, p.395-401, 2001.

STRECK, E.V.; KÄMPF, N.; DALMOLIN, R.S.D.; KLAMT, E.; NASCIMENTO, P.C.; SCHNEIDER, P. Solos do Rio Grande do Sul. Porto Alegre, Universidade Federal do Rio Grande do Sul, 2002. 126p.

TORRES, E.; SARAIVA, O.F. Camada de impedimento do solo em sistemas agrícolas com soja. Londrina: Embrapa Soja, 1999. 58p. (Embrapa Soja. Circular Técnica, 23)

TREIN, C.R.; COGO, N.P.; LEVIEN, R. Métodos de preparo do solo na cultura do milho e ressemeadura do trevo, na rotação aveia + trevo/milho, após pastejo intensivo. Revista Brasileira de Ciência do Solo, v.15, p.105-111, 1991. 